
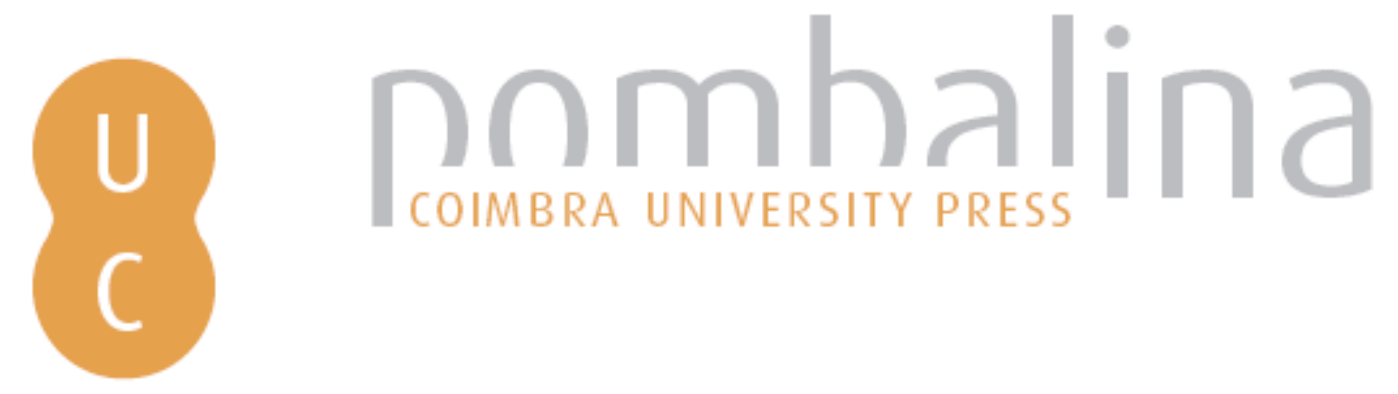

\title{
Turismo e fronteiras: uma relação dinâmica entre o turismo cultural e político
}

Autor(es): $\quad$ Fernandes, João Luís Jesus

Publicado por: Imprensa da Universidade de Coimbra

URL persistente:

URI:http://hdl.handle.net/10316.2/43526

DOI:

DOl:https://doi.org/10.14195/978-989-26-1343-7_30

Accessed : $\quad$ 26-Apr-2023 13:22:26

A navegação consulta e descarregamento dos títulos inseridos nas Bibliotecas Digitais UC Digitalis, UC Pombalina e UC Impactum, pressupõem a aceitação plena e sem reservas dos Termos e Condições de Uso destas Bibliotecas Digitais, disponíveis em https://digitalis.uc.pt/pt-pt/termos.

Conforme exposto nos referidos Termos e Condições de Uso, o descarregamento de títulos de acesso restrito requer uma licença válida de autorização devendo o utilizador aceder ao(s) documento(s) a partir de um endereço de IP da instituição detentora da supramencionada licença.

Ao utilizador é apenas permitido o descarregamento para uso pessoal, pelo que o emprego do(s) título(s) descarregado(s) para outro fim, designadamente comercial, carece de autorização do respetivo autor ou editor da obra.

Na medida em que todas as obras da UC Digitalis se encontram protegidas pelo Código do Direito de Autor e Direitos Conexos e demais legislação aplicável, toda a cópia, parcial ou total, deste documento, nos casos em que é legalmente admitida, deverá conter ou fazer-se acompanhar por este aviso. 


\section{FERNANDA CRAVIDÃO}

\section{IÚCIO CUNHA}

PAULA SANTANA

\section{NORBERTOSANTOS}

(ORG.)

\section{ESPAÇOS E TEMPOS EM GEOGRAFIA}

HOMENAGEM A ANTÓNIO GAMA

IMPRENISA DÁ UNIVERSIDADE DE COIMBRA COIMBRA UNIVERSITY PRESS

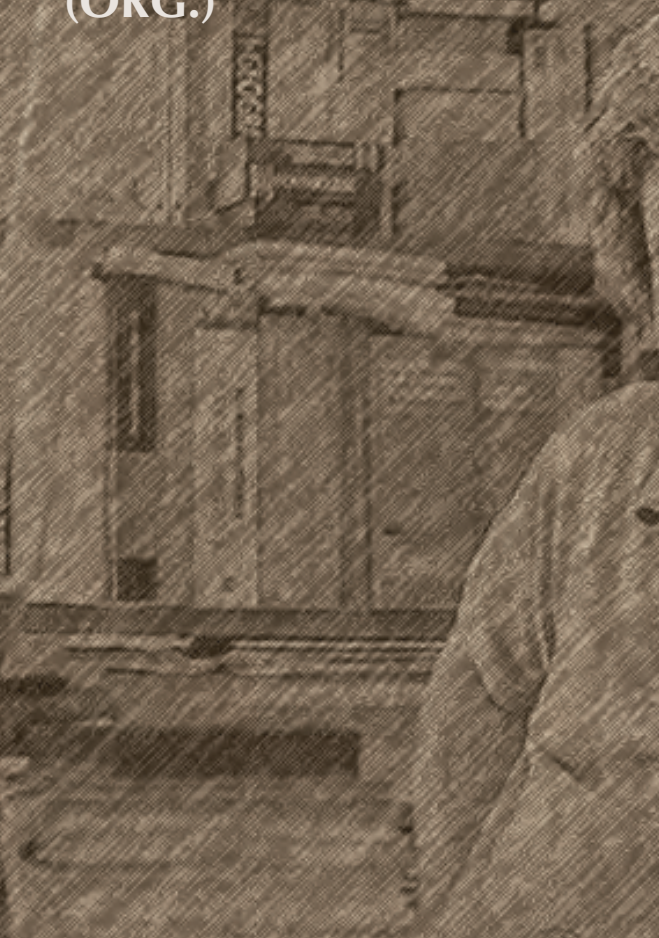




\title{
TURISMO E FRONTEIRAS: UMA RELAÇÃO DINÂMICA ENTRE O TURISMO CULTURAL E POLÍTICO
}

\author{
João Luís Jesus Fernandes/jfernandes@fl.uc.pt \\ Departamento de Geografia e Turismo \\ da Faculdade de Letras da Universidade de Coimbra \\ e CEGOT
}

O turismo é um processo territorial, consumidor mas também modelador de paisagens. Nesse sentido, existe uma relação múltipla e instável entre a atividade turística e o espaço geográfico, entendido este último na sua multidimensionalidade e nos diferentes elementos que o compóem e (des)estruturam.

Entre estes, encontram-se os limites, as fronteiras, os muros e todas as expressóes, materiais e/ou imateriais, mais visíveis ou mais discretas, de fragmentação do espaço. O turismo apresenta, com estas linhas ou áreas divisórias, uma relação complexa e diversificada. Considerando a fronteira não na sua concetualização mais restrita (de limite político separador de dois Estados), mas no seu mais lato sentido de demarcação, é possível estabelecer uma relação múltipla entre esta e os espaços turísticos.

Por um lado, o turismo expandiu-se alargando as fronteiras dos seus territórios, ultrapassando obstáculos, entrando em espaços antes não equacionados enquanto lugares de lazer, fruição ou consumo turístico.

Por outro, estas fronteiras constituem, elas próprias, um património de atração de turistas que, seguindo múltiplas motivaçóes, as procuram para observar, fotografar, para estar ali, no extremo, ou simplesmente para o seu atravessamento. 
Por último, o turismo e as fronteiras cruzam-se num outro sentido. O turista hipermobilizou-se porque ultrapassou barreiras, viaja porque algumas destas o atraem mas é importante sublinhar que este turista e esta atividade turística criam também as suas próprias fronteiras. Referia-se atrás que o turismo modela a paisagem, isto é, que pode deixar um rasto no espaço geográfico. Um dos elementos territoriais que podem resultar do turismo enquanto atividade inovadora é a construção de novas demarcaçôes e fronteiras, o levantamento de lógicas e dinâmicas, até então inexistentes, de fragmentação do espaço.

\section{$\mathrm{O}$ turismo entre as dinâmicas que permeabilizam fronteiras e os muros que persistem}

A relevância ambiental, social, económica mas também cultural e política do turismo, resulta em parte da sua expansão e resiliência espacial. Enquanto atividade múltipla, o turismo cresceu porque foi alargando a sua espacialidade e acrescentando territórios turísticos. Numa dinâmica que é outra das faces da hiperaceleração e do sempre necessário investimento do capital em excesso (Harvey, 2011), as cartografias do turismo e do turista alargaram-se, tornaram-se flexíveis, difíceis de registar e acompanhar, facto que deriva da própria dificuldade em regular uma sociedade agora marcada pelos ritmos múltiplos e diferenciados de mobilidade e pela emergência de um novo nomadismo (Urry, 2007).

Neste ponto de vista, o turismo é expressão de uma globalização que encolheu distâncias, ultrapassou barreiras, permeabilizou fronteiras (Harvey, 2002). Em muito alicerçada em processos de inovação tecnológica e institucional aplicada aos transportes, esta distenção deve muito à evolução de setores como a aviação, que parece ter tornado o mundo mais pequeno e acessível (Groening, 2014), num planeta agora plano, sem as rugosidades do espaço e sem limites (Omahe, 1999; Friedman, 2005).

É verdade que esta compressão espaço-tempo foi impulsionada pelo turista que dispóe de mais tempo e recursos para investir na viagem. No entanto, a territorialidade deste alargou-se e flexibilizou-se em consonância com a geografia 
dos portos e dos aeroportos, das rotas marítimas organizadas mas também dos voos charter ou das companhias low cost.

Ainda que agora se aponte o slow tourism como alternativa terapêutica (Yurtseven e Kaya, 2011), o turismo alargou fronteiras porque se transportam viajantes a velocidades crescentes, aquela que, na janela de um aviáo, nos mostra um mundo, na aparência, sem barreiras nem obstáculos (Groening, 2014).

Enquanto atores em movimento da ethnoscape de Appadurai (2004), o turista integrou espaços geográficos como a Amazónia e a Antártida, o Tibete ou a Patagónia. Em relação aos mais importantes pontos de partida e difusão do consumo turístico, estes são territórios longínquos que se tornaram acessíveis. Em primeiro lugar, para uma elite de pioneiros e vanguardistas com o poder de arrastar outras procuras, que se vão alargando, porventura até massificando, para logo de seguida, num ciclo de crescimento constante, o sistema se expandir, com o consequente derrube de outras barreiras espaciais.

Nestas procuras múltiplas, o turismo expande-se para o lugar idílico, para o território estereotipado do sol, da palmeira, da areia branca e das águas transparentes, mas também para o anti-idílico, para a favela no Rio de Janeiro, para os perímetros radioativos de Chernobyl, para os campos da morte de Auschwitz ou para cemitérios que, ora assinalam as biografias de celebridades (como no Père Lachaise, em Paris), ora recordam acontecimentos traumáticos de guerras e outros conflitos armados (como os cemitérios que evocam a I Guerra Mundial, na Flandres).

Com este turismo expansivo e elástico, os muros que separam estas traumascapes tornam-se permeáveis a este novo consumo. Por múltiplas razóes, as portas abrem-se ao turista que, deste modo, entra num território reservado. Esta entrada faz-se por uma constelação complexa de motivaçôes, da simples curiosidade ao interesse académico e cultural, do desejo de atravessar esses limites, a qualquer evocação ou a uma mais séria e profunda celebração e devoção.

Sustentada por esta diversidade de interesses, a difusão do turista e da atividade turística cria uma sensaçáo de ubiquidade, do turismo que pode estar em todo o lado e a toda a hora, de um mundo sem fronteiras nem limitaçóes de acesso ou, pelo menos, de um mundo no qual ao turista é reservado um 
corredor especial de entrada e circulação, uma porta que todos os lugares abrem para assim participarem nesta festividade global.

Apesar disso, a perceção da fluidez desse movimento sem fronteiras nem obstáculos é apenas uma das faces da realidade. Na verdade, persistem obstáculos ao movimento do turista. Mesmo nas viagens de avião, aquelas que parecem avançar num espaço sem barreiras, a aeronave progride num território regulado, fragmentado e limitado por restriçóes de acesso. À medida que as apropriaçóes espaciais se foram alargando, a lógica das fronteiras foi-se também deslocando, da terra para o mar e deste para o espaço aéreo (Sofield, 2006).

Por isso, o turista não tem total liberdade de movimento. Há restriçóes e regulaçóes sustentadas por múltiplos fatores, daqueles que podem derivar da limitada capacidade de carga, dos condicionalismos climáticos e de conforto, mas também de outros, mais complexos e de natureza política.

A mobilidade espacial do turista é também regulada pela exigência, ou não, de um visto de entrada em determinados espaços políticos. Este requisito é um fator de orientação e condicionamento desses fluxos, que irão encontrar destinos mais ou menos permeáveis.

Consultando o The Henley \& Partners Visa Restrictions Index (Henley \& Partners, 2015), é possível quantificar o maior ou menor potencial de atravessamento de fronteiras das diferentes nacionalidades e passaportes. Desde os cidadãos da Alemanha e do Reino Unido, que não necessitam solicitar um visto para aceder a 173 países, até aos viajantes com passaporte do Afeganistão (apenas não têm que pedir um visto de entrada em 25 países), é muita a diversidade.

Enquanto requisito de atravessamento de uma fronteira, o visto pode ser um fator de dissuasão e disciplina deste movimento turístico que, afinal, é sensível às rugosidades do espaço geográfico (Blij, 2009). É assim, deste modo assimétrico de regulação, que se promovem alguns destinos e se salvaguardam outros. É também deste modo que os lugares selecionam os visitantes e turistas e determinam os respetivos tempos de estada. A regulação deste turismo que, afinal, não pode estar em todo o lado, é por vezes seletiva, como se verificou com as limitaçóes de acesso a Cuba que turistas provenientes dos EUA chegaram a sentir em virtude da inexistência de relaçóes diplomáticas entre os dois 
países. O mesmo ocorre, num outro exemplo, com a dificuldade de acesso de turistas israelitas a países como a Tunísia ou outros territórios islâmicos, como retaliaçáo pelo conflito israelo-árabe.

Nesta instrumentalização do turismo enquanto arma diplomática, as restriçóes e impedimentos podem ter origem no país emissor, como ocorreu em 2015 com a atitude do Estado russo ao desviar os seus turistas de um país com o qual vivia um diferendo político, a Turquia.

Neste território turístico expansivo é possível identificar áreas 'no-go' determinadas pelos espaços de chegada, lugares de acesso restrito ou mesmo proibido, espaços de exclusão ou forte condicionamento para turistas que, apenas com autorizaçóes especiais, poderão atravessar determinados limites, como ocorre em países como Myanmar. Em áreas militares, territórios fronteiriços sensíveis ou espaços de tensão política (como o Tibete), entre a proibição total e as possibilidades condicionadas de acesso, as restiçóes são variadas: nalguns casos, podem fazer-se visitas de dia, mas não de noite; noutros, a entrada pode fazer-se em grupos, devidamente orientados por guias credenciados, mas já não em viagens e trajetos individuais. Noutros lugares existem restriçóes de género: entrarão os homens mas não as mulheres.

Nestas estratégias defensivas, o turista pode ser um intruso que perturba uma certa ordem e disciplina: por quebrar códigos mais restritos de conduta, por ser uma testemunha indesejável ou até mesmo, segundo Smith (2003), por simbolizar a frente avançada das potências hegemónicas que, deste modo, através do turismo, quererão alargar a sua influência.

$\mathrm{O}$ comportamento das comunidades locais em relação à procura turística pode ser entendido como uma outra frente de resistência que se levanta perante os poderes exógenos. Para Machá (2013: 91), o grau de aceitação/condicionamento/rejeição do turista nos pueblos do Novo México (EUA) é exemplo dessa instrumentalização política do turista: "When taking a photo of the old adobe church in the Hispanic village of Córdova in north-central New Mexico, a man ran out of a near-by house, cursed, half in Spanish, half in English, and told me that photography was not allowed. When I inquired why, he simply said that the priest forbade it. Then he left in a pick-up truck and a few window curtains 
slightly moved as we walked out of the village. While used to such reactions in Native American reservations in the area, I was surprised by the existence of such a prohibition in a Hispanic village. This experience which later proved to be one of several more made me think about the wider context of such reactions to tourism and led me to a conclusion that in order to understand the dynamics of tourism in a given place from an anthropological or cultural-geographical perspective we must study not only the 'tourist encounter' (...), that is, the relations and interactions between tourists and locals, but also to analyze the wider social relations between different groups of locals and between locals and their governments. From this perspective the tourist may emerge not only or even primarily as as a convenient source of income for a profit-driven global enterprise or as a 'terrorist' (...) but rather as a 'pawn' in a game with a much greater importance, a game over the control of resources, the obtainment and safeguarding of group rights and symbolic recognition".

De acordo com o autor, neste Estado norteamericano as comunidades locais limitam a liberdade de movimento, fecham ou abrem portas ao turista, promovem ou não certos comportamentos do visitante de acordo com a mensagem que pretendem enviar ao Estado Federal, sempre na lógica de afirmar o seu poder de decisão sobre o seu território.

Nesta perspetiva, o turista não é apenas o ator que desloca capital económico, mas é também testemunha e veículo de uma mensagem política. Por outro lado, o poder não está apenas em quem viaja, mas também nas comunidades de acolhimento que, deste modo, instrumentalizam o turista de acordo com os seus interesses, que vão muito além do aspeto material.

\section{O turismo que procura e é atraído por fronteiras e demarcaçóes espaciais}

Os limites, as barreiras e as fronteiras constituem meios de condicionamento dos fluxos turísticos e instrumentalização dos turistas, personagens sobre as quais se concentram os principais focos de atenção. Aceitar ou rejeitar o turismo é, por isso, um ato de relevância política. No entanto, estas demarcaçóes espaciais 
constituem, elas próprias, um atrativo e um objeto de interesse e desejo por parte do turista, num processo que se manifesta em várias escalas geográficas e em diferentes contextos, facto que confere com a já citada conceção difusa e multidimensional de fronteira.

Por exemplo, em áreas rurais como o Parque Natural das Serras de Aire e Candeeiros, os muros constituem um dos elementos da paisagem cultural que atrai turistas a esta área classificada. Neste território do Maciço Calcário Estremenho, estas demarcaçôes de pedra calcária criam um rendilhado de muros com múltiplas funcionalidades, como a separação entre as terras; a limpeza dos solos pedregosos; a definição de caminhos; o encerramento do gado em perímetros protegidos e a fixaçáo da humidade. A tudo isto, acrescenta-se o valor estético de uma paisagem cultural protegida, agora objeto de apropriação por parte do turista.

Como os moinhos, as levadas ou algum edifício religioso, os muros acrescentam densidade cultural a estas paisagens rurais (Firmino, 2015), dão-lhe carácter e imprimem-lhe uma identidade, valores no centro das procuras turísticas nestes espaços geográficos de baixas densidades, como ocorre, num outro exemplo, com os Stone Walls rurais em paisagens como as da República da Irlanda (MacWeeney e Conniff, 1986).

Noutras circunstâncias, recorrendo a um outro conceito de limite, o turista é atraído por muros e fronteiras apenas porque quer atravessar essas demarcaçóes e ser reconhecido por isso. Por aqui passa um certo colecionismo de carimbos de passaporte e países visitados, num simbolismo testemunhado, por exemplo, pela acumulação e exibição de autocolantes geográficos nas velhas malas de viagem. É por aqui, por registos que agora passaram do analógico às plataformas digitais, que se expóem cartografias pessoais que atestam o viajante como cosmopolita e conferem a esse turista um estatuto e perfil que lhe trará prestígio e notoriedade.

Essa glorificação é justificada por se ter ido mais longe, a lugares remotos, atravessando uma fronteira civilizacional. Por isso se vai ao extremo em Ushuaia, na Patagónia, cidade do fim do mundo, a última do Hemisfério Sul. Para além dela está a Antártida, onde se quer entrar, como se gosta também de penetrar na 
Amazónia, no deserto do Saara ou nas altitudes do Nepal, porque se atravessa uma barreira de separação e, de certo modo, no imaginário coletivo, se entra num área demarcada apenas acessível aos mais aventureiros.

Este turismo de limites apropriou fronteiras e muros históricos, muralhas, fortes e fortins, em rotas patrimoniais que, em diferentes escalas geográficas e contextos, recordam as fragmentaçóes e as lógicas de separação e medo do passado. Lição de História e experiência cultural, estas velhas barreiras que, outrora, afastavam o Outro, passaram a lugares de atração e comunhão de valores, como os fragmentos do Muro de Berlim expostos na capital alemã mas também noutros lugares do mundo, como Fátima.

Nalguns casos, aqueles inscritos na lista de sítios Património Mundial da Unesco, os espaços de afastamento do passado representam agora os valores universais de uma herança planetária comum. Assim ocorre com as muralhas e com o sistema fortificado de Elvas, património mundial que se formou na lógica das oposições políticas e militares no contexto ibérico. $\mathrm{O}$ mesmo se pode afirmar a respeito da Grande Muralha da China, classificada pela Unesco como valor universal mas construída para defesa do império chinês face ao risco de invasão pelas tribos nómadas do norte.

Para Faucher (2007), os muros e as fronteiras são espaços relevantes que atraem, facto que tem levado o turista a procurar demarcaçóes históricas mas a não contentar-se com estes vestígios de um passado receoso e turbulento. Por isso, não excluindo estas demarcações pretéritas, o território turístico alargou-se também para as fronteiras vivas da atualidade (Cintio, 2012), numa vivência que, segundo Gelbman (2010), pode ser uma via para a aproximação entre as partes, num pro peace tourism que será também uma atitude política.

Podem incluir-se aqui os territórios fronteiriços permeáveis que partilham estratégias patrimonais e procuram heranças comuns, como ocorre nalguns casos na raia entre Portugal e Espanha. Mas devem ainda incluir-se procuras como a atração turística pelos muros da Cisjordânia, pela fronteira entre o México e os EUA ou, num outro exemplo, por Wagah, que separa a Índia e o Paquistão, lugar no qual, todos os dias, se celebra um ritual de descerramento das bandeiras dos dois países e afirmação simbólica da soberania de cada um. 
Nesta perspetiva, os exemplos abundam. Numa das mais fragmentadas cidades europeias - Belfast, o turista procura as inscriçóes urbanas que veiculam mensagens políticas, assim como os muros que separam territórios de maioria católica ou protestante, barreiras de delimitação que segregam este espaço urbano mas que atraem os curiosos e interessados numa lógica de conflitualidade política que a União Europeia atenuou mas não fez desaparecer (Calame e Charlesworth, 2009).

Para Kevin Lynch (1999), os limites e as barreiras são um dos elementos que se destacam na cityscape. Neste turismo urbano, valoriza-se a experiência de ver e sentir essa fronteira, de a atravessar, entrar num determinado perímetro, visitar um bairro, como a Mouraria (em Lisboa), ou as medinas das cidades norte-africanas, penetrar no mesmo e voltar a sair, por vezes através de uma porta que adquire o estatuto de ícone (como a Porta de Almedina, através da qual se entra e sai da Alta coimbrã).

O mesmo ocorre em enclaves de natureza étnica, nas chinatowns de cidades como Londres ou Nova Iorque, áreas demarcadas que são uma oportunidade para experienciar um certo oriente exótico "without undertaking transpacific travel” (Lin, 1998: 171).

Noutro contexto, no Rio de Janeiro, visitar uma favela como a Rocinha implica o atravessamento de um limite e a entrada num mundo vedado, cujo acesso apenas será possível ser orientado e conduzido por guias locais que assim ganham relevância acrescida, porque apenas estes possuirão a chave para se ir e vir em segurança, sem confrontos com as lógicas de poder territorial que existem para além daqueles muros de separação.

Mas é também nas áreas protegidas que o turista gosta de atravessar fronteiras e portas de penetração, como acontece nos parques nacionais africanos. Para além do limite de Masai Mara ou Tsavo, está o território idílico da natureza selvagem, o mundo que resistiu às mudanças impostas pela civilização, o cenário cinematográfico dos big five, do leão e do leopardo.

Atravessar uma fronteira pode implicar isso mesmo, a entrada num mundo escondido, num segredo como a Coreia do Norte visitada por José Luís Peixoto (2012). Nessa perspetiva, o viajante é uma testemunha, uma 
voz que trará uma mensagem sobre algum território protegido dos olhares dos outros.

Este turista atraído por limites e perímetros, porque quer experienciar essa barreira ou simplesmente porque a quer atravessar para penetrar em territórios reservados (como a Cidade Proibida, em Pequim), é o mesmo que gosta de estar, ao mesmo tempo, nos dois extremos da fronteira. Quer ir e voltar mas quer também representar-se como aquele cosmopolita que assenta os pés nos nos dois lados da muralha, um no hemisfério ocidental, outro no oriental, sobrepondo-se ao Meridiano de Greenwich, fronteira imaterial que ali está, na periferia de Londres, ao seu dispor e alcance, para uma fotografia que testemunhe que o turista ali esteve, naquela posição de equilíbrio.

Ainda assim, neste mundo fraturado por muros e demarcaçóes (Jones, 2012), o turista que atravessa fronteiras e é atraído por elas, é também responsável pela criação de (novas) linhas e áreas de separação. Enquanto ator geográfico, este mesmo turista pode ser um fator de segregação e fragmentação do espaço.

\section{O turismo que constrói as suas próprias fronteiras, barreiras e limites}

São vários os autores que têm estudado a atividade turística como uma dinâmica contraditória que cria territórios de enclave (Lew, 2004), assumindo o turismo como uma espécie de "suspending reality" (Wilson e Richards, 2008), ou uma "tourist bubble" (Judd, 1999).

Nalguns casos, o alargamento espacial do turismo faz-se por confinamentos e por novos muros que se levantam. Assim ocorre com muitos resorts, que se expandem apropriando e privatizando solos, levantando fronteiras entre o que está dentro e o que fica do lado de fora. Neste turismo insular de idílios paradisíacos, o turista é enclausurado num perímetro higienizado que o protege de um exterior entendido como agressivo e distante. Neste enclave garante-se o convívio com o semelhante, com o turista que chegou de outro ponto do mundo ocidental mas que comunga e partilha os mesmos interesses. Nas palavras de Mark Ganovetter (1973), este é o espaço dos strong ties, daquelas 
partilhas que se estabelecem entre iguais. Por contraposição, o muro vigiado esconde as comunidades locais e afasta o risco dos weak ties, os laços fracos que se estendem entre os canais e as experiências de interculturalidade que este modelo turístico não promove.

Estes muros condicionam os olhares do turista, afastam-no dos hipotéticos problemas de desenvolvimento humano do exterior. Ao mesmo tempo, podem reforçar as visōes estereotipadas. O Outro, o habitante local, está escondido, não se vê, porventura toma-se contacto com a sua imagem ou com uma versáo padronizada e estilizada do mesmo - o touree que se mostra como típico, o xingu ou o massai que vai ao encontro do imaginário do turista que, afinal, esteve lá, num mundo remoto ainda habitado por povos exóticos intemporais.

Este turismo muralhado tem também expressão nos parques temáticos, territórios de lazer e entretenimento que concentram as atençóes e os consumos. Entrar implica não sair para contactar ou usufruir de serviços no exterior. $\mathrm{O}$ bilhete não permite deambulaçôes entre o dentro e o fora, evitando-se assim qualquer dispersão para o mundo que está para além do muro.

A cartografia de promoção destes perímetros muralhados - os resorts e os parques temáticos, são reveladores dessa estratégia autocentrada. Focados nos perímetros que pretendem publicitar, recorrem ao que Monmonier (2010) denominou como cartografia imperativa, isto é, cartogramas que condicionam a perceçáo e os comportamentos. Representando e posicionando os resorts e os parques temáticos no centro daquele mundo, nada mostram para além dos muros divisórios e protetores. Nesta supressão e simplificação do espaço geográfico, depois das fronteiras separadoras nada existe, é um espaço abstrato, sem vida nem materialidade, com uma cor uniforme e discreta, uma homogeneidade indiferenciada apenas, porventura, interrompida pelas vias de comunicaçáo que orientam os fluxos para as entradas, no caso dos resorts, desses paraísos de sol, areia branca, palmeiras e água transparente.

Nesta perspetiva da criação de espacialidades de enclave, os resorts e os parques temáticos levantam muros para criar um espaço geográfico que é, em exclusivo, um território turístico, de e para turistas, sem interferências de outros atores. Em paralelo, incorre-se no risco da desterritorialização (Haesbaert, 2004), da 
supressão de espaço para aqueles que não são turistas, atores que se deverão reterritorializar a partir dessas opçóes geográficas comprimidas e condicionadas.

Este impacto pode ocorrer num outro perímetro muralhado turístico, um muro que isola espaços para o território exclusivo do praticante de golfe, demarcando um paraíso verde de difícil acesso.

Os muros existem e são levantados por modelos turísticos de elite. No entanto, como se escreveu a propósito dos parques temáticos, nalguns aspetos o turismo mais massificado não deixa também de levantar as suas barreiras e definir as suas formas e modos de enclausuramento. Em muitos casos, a experiência turística de massas organiza-se por ilhas humanas em movimento, pelo touring orientado por guias que elevam bandeiras ou outros sinais de agregação, diferenciando o grupo de todos os que ficam fora desse perímetro, numa segregação espacial quantas vezes consolidada pelo idioma: russo para os turistas que chegaram de Moscovo ou Sampetersburgo, mandarim para os que vieram da China.

Neste ponto de vista, o recurso a dispositivos eletrónicos e pessoais orientados por GPS, cria um território turístico individualizado e o enclausuramento do turista num mundo exclusivo, sem contacto com o exterior.

Noutros casos, após o atravessamento de certos limites, após a entrada na favela ou no parque natural, o turista enclausura-se em cápsulas de proteção, para ver sem ser visto, como se se tratasse de um panóptico que protege o observador, mas que o faz movimentar entre muralhas. Este invólucro protetor será uma espécie de torre de marfim móvel que permite ao turista observar e tirar a fotografia em segurança num território que é suposto ser perigoso.

A própria expansão territorial do turismo faz-se através destes compartimentos protetores. O turista movimenta-se por canais de viagem, muitas das vezes sem contacto com a realidade extramuros. Weaver (2005) referia-se aos cruzeiros como uma forma de enclave que apenas pontualmente se abre ao exterior.

Em muitos casos, o usufruto está no percurso em si, no trajeto, ainda que este seja feito numa carruagem, num transporte confinado que se movimenta mas que protege o turista, naquele que será um turismo de observação mas não de contacto, com um viajante que vê à distância mas que não se aproxima. 
Esta é a lógica da viagem rápida em turismo, como aquela que ocorre num aviāo, num espaço topológico que em muito contribuiu para a compressão do espaço e do tempo. Para Groening (2014), a viagem aérea é também uma experiência de enclausuramento dos corpos enquanto condição para vencer as distâncias. Viaja-se rapidamente para o destino, tem-se uma visão aérea (e oblíqua) de uma parte da superfície terrestre. No entanto, continua Groening (2014), tudo isto ocorre com o encarceramento do passageiro que se vai distraindo com conteúdos de uma indústria de entretenimento que viu nos avióes um dos seus territórios de expansão.

Nesta perspetiva, e enquanto sustento principal do turismo, a aviação comercial tem vencido fronteiras, mas tem criado outras. Ainda para Stephen Groening (2014), para além da fragmentação política e de soberania do espaço aéreo, na aeronave impóe-se uma outra fronteira, um limite de modo subtil demarcado por uma cortina: a separação entre os lugares de classes executivas e os restantes. Para o autor, esta estratificação reflete as barreiras existentes nos aeroportos, talvez um dos lugares mais condicionados pelo sentido de fronteira.

Por um lado, o aeroporto internacional criou fronteiras políticas onde estas não existiam: os limites de Portugal com o exterior já não coincidem em exclusivo com os limites externos do território nacional (a raia), para passarem a existir também nos territórios dos aeroportos internacionais de Lisboa, Porto ou Faro, por exemplo.

Por outro, o aeroporto é o espaço da vigilância, do escrutínio, do controlo, da regulação e disciplina, mas também o lugar, ou não-lugar, segundo Augé (1998), dos VIP Lounges bem delimitados, das barreiras entre as classes populares e as classes premium, naquela que é, em terra, a reprodução da hierarquia que depois se experiencia na aeronave.

Mas o turismo é isso mesmo, uma dinâmica que levanta muros que apenas podem ser atravessados por quem cumprir certos requisitos, por quem pagar o bilhete, quem respeitar determinadas regras de etiqueta no vestuário e no comportamento, quem adquirir os códigos de acesso. No turismo de massas, essa aquisição e esse estatuto podem passar por uma marca, um registo no próprio corpo, uma pulseira colorida que permite entrar e sair. Símbolo de 
diferenciação, esse passaporte confere um estatuto e um privilégio: naqueles dias, o turista faz parte daquele território insular, daquele hotel demarcado do exterior mas ao qual pode aceder, circulando por múltiplos espaços, usufruindo de serviços, atravessando muros de acesso e demarcaçáo.

\section{Notas finais}

O turismo não é uma atividade neutra nem linear. Pelo contrário, a dinâmica turística é um processo complexo e, por vezes, contraditório. Por um lado, cresceu e difundiu-se no espaço porque a sociedade lhe votou mais tempo e capital, porque novos paradigmas (re) valorizaram velhos e novos contextos geográficos e suscitaram procuras, mas também porque os transportes, para certos atores e consumidores, encurtaram algumas distâncias e estenderam o significado e a dimensão da viagem.

Ainda assim, e partindo de um conceito lato e difuso de fronteira, o turismo está também associado a um mundo rugoso, lento, fragmentado, marcado por limites, barreiras e muros de diferente natureza.

A relação do turismo e do turista com essas linhas (ou áreas) de descontinuidade e separação tem que ser vista de modo amplo. Por um lado, pela capacidade do turista em ultrapassar esses obstáculos, mas também pelo modo como, por vezes, estes continuam a condicionar esses fluxos.

No entanto, o turismo procura fronteiras, encontra motivação para ir ao seu encontro e, por vezes, para ultrapassá-las, ainda que estas estejam em lugares remotos, longe dos centros urbanos organizadores do território. Ainda assim, os limites históricos e os atuais, numa procura algures entre o turismo cultural e político, são pontos de atração. Ir a uma fronteira turbulenta é uma aventura mas pode ser também uma experiência política, uma tomada de posiçáo, uma oportunidade para estar naqueles lugares que, afinal, mostram que o mundo não é plano.

Antes pelo contrário, nalguns casos o turismo é responsável por essas rugosidades. Não apenas porque as consome mas também porque levanta novos 
limites e barreiras, novas superfícies de não contacto e muralhas de exclusão e segmentação. Este turismo de hipermobilidade que atravessa o mundo, deixa um rasto geográfico de muros e fronteiras, de territorialidades condicionadas, as dos turistas confinados em resorts ou parques temáticos, mas também as de algumas comunidades locais que veem as suas espacialidades encolhidas e as suas opçóes territoriais limitadas. Nestes e noutros estudos de caso, abre-se aqui um campo para a análise geográfica das relaçóes de poder, aquelas que vão ampliando (ou encurtando) as territorialidades dos diferentes atores.

\section{Bibliografia}

Appadurai, A. (2004). Dimensōes culturais da globalização. Lisboa: Teorema.

Augé, M. (1998). Não-Lugares. Introdução a uma antropologia da sobremodernidade. Venda Nova: Bertrand Editora.

Blij, H. de (2009). The power of place. Geography, destiny and globalization's rough landscape. Oxford: Oxford University Press.

Calame, J. \& Charlesworth, E. (2009). Divided cities. Belfast, Beirut, Jerusalem, Mostar, and Nicosia. Philadelphia: University of Pennsylvania Press.

Cintio, M. di (2012). Walls. Travels along the barricades. London: Union Books.

Firmino, A. (2015). Stone functionalities and sustainable landscapes. Carpathian Journal of Earth and Environmental Sciences, August 2015, Vol. 10, N.o 3, pp. 189-196.

Foucher, M. (2007). L'obsession des frontiers. Paris: Perrin.

Friedman, T. (2005). The world is flat. New York: Farrar, Straus and Giroux.

Gelbman, A. (2010). Border tourism attractions as a space for presenting and symbolizing peace. In Moufakkir, O. \& Kelly, I. (ed.). Tourism, Progress and Peace (83-98). Wallington: Cabi.

Granovetter, M. (1973). The strength of weak ties. American Journal of Sociology, v. 78, Issue 6, pp. 1930-1938.

Groening, S. (2014). Cinema beyond territory. Inflight entertainment and atmospheres of globalisation. London: Palgrave Macmillan.

Haesbaert, R. (2004). O mito da desterritorialização. Rio de Janeiro: Bertrand Brasil.

Harvey, D. (2002). The condition of postmodernity. Cambridge: Blackwell.

Harvey, D. (2011). O Enigma do capital e as crises do capitalismo. Lisboa: Bizâncio.

Henley \& Partners (2015). The Henley \& Partners Visa Restrictions Index. In visaindex.com/\# (consultado a 21 de março).

Jones, R. (2012). Border walls. Security and war on terror in the United States, India and Israel. London and New York: Zed Books. 
Judd, D.R. (1999). Constructing the tourist bubble. In D. R.Judd \& S. Fainstein (eds), The Tourist City. New Haven: Yale University Press, pp. 35-53.

Lew, A. (2004). Editorial: Tourism enclaves in place and mind. Tourism Geographies 6 (1), p. 1.

Lin, J. (1998). Reconstructing Chinatown. Ethnic enclave, global change. Minneapolis: University of Minnesota Press.

Lynch, K. (1999). A imagem da cidade. Lisboa: Edições 70.

Mácha, P. (2013). Resistance through tourism: Identity, imagery, and tourism marketing in New Mexico. In J. Sarmento \& E. Brito-Henriques (eds.), Tourism in the Global South: Heritages, Identities and Development. Lisbon: University of Lisbon, pp. 91-112.

MacWeeney, A. \& Conniff, R. (1986). The stone walls of Ireland. London: Thames and Hudson.

Monmonier, M. (2010). No dig, no fly, no go. How maps restrict and control. Chicago: The University of Chicago Press.

Omahe, K. (1999). The Borderless world. Power and strategy in the interlinked economy. New York: McKinsey \& Company, Inc.

Peixoto, J. L. (2012). Dentro do segredo. Lisboa: Quetzal.

Smith, M. K. (2003). Issues in cultural tourism. Routledge: London.

Sofield, T. (2006). Border tourism and border communities: An overview. Tourism Geographies, An International Journal of Tourism Space, Place and Environment, vol.8, issue 2, pp. 102-121.

Urry, J. (2007). Mobilities. London: Polity.

Yurtseven, R. \& Kaya, O. (2011). Slow tourists: A comparative research based on cittaslow principles. American International Journal of Contemporary Research, Vol. 1 N. ${ }^{\circ}$ 2, pp. 91-98.

Weaver, A. (2005). Spaces of containment and revenue capture: 'Super-sized' cruise ships as mobile tourism enclaves. Tourism Geographies 7 (2), pp. 165-184.

Wilson, J. \& Richards, G. (2008). Suspending reality: An exploration of enclaves and the backpacker experience. Current Issues in Tourism, Vol. 11, N. ${ }^{\circ}$ 2, pp. 187-202. 